INFLAMMATORY BOWEL DISEASE

\title{
Systemic antibodies towards mucosal bacteria in ulcerative colitis and Crohn's disease differentially activate the innate immune response
}

\author{
E Furrie, S Macfarlane, J H Cummings, G T Macfarlane
}

Gut 2004;53:91-98

See end of article for authors' affiliations

Correspondence to: Dr E Furrie, MRC Microbiology and Gut Biology Group, University of Dundee, Ninewells Hospital Medical School, Dundee DDI 9SY, UK e.furrie@dundee.ac.uk

Accepted for publication 30 May 2003

\begin{abstract}
Background and aims: The mucosa in ulcerative colitis (UC) is replete with antibody producing plasma B cells and polymorphonuclear leucocytes (PMN). This combination of effector cells requires a crosslinking antigen to evoke an antibody driven PMN inflammatory response via their Fc receptors. The stimulus for activation is thought to be commensal bacteria colonising the gut mucosa. The aim of this investigation was to compare the principal culturable bacterial populations on the rectal mucosa of UC patients, and to determine whether specific antibodies towards these bacteria can activate infiltrating PMN through opsonisation. This would provide an explanation for this chronic inflammatory condition.

Methods: Bacteria colonising rectal tissue were characterised using chemotaxonomic techniques. Systemic antibody responses were measured against total antigens and surface antigens of these organisms in UC and Crohn's disease (CD) patients, together with healthy controls. Antibody enhancement of the respiratory burst in PMN was also investigated, against a range of mucosal isolates.

Results: Distinct differences were observed in some bacterial populations in UC biopsies, which were generally reflected in antibody responses towards these organisms. UC patients had higher lgG responses to surface antigens, primarily lgGl, whereas the response in $C D$ was mainly lgG2. Antibodies from UC patients greatly enhanced the respiratory burst in PMN, in response to individual bacterial species.

Conclusions: Changes in mucosal bacteria, and a switch from internal to surface antigen/antibody reactivity of a predominantly $\lg \mathrm{G} 1$ type, leads to greater opsonisation of the respiratory burst in PMN, providing a mechanism for maintaining the inflammatory state in UC.
\end{abstract}

nflammatory processes in ulcerative colitis (UC) usually begin in the distal bowel, and progress proximally along the mucosa, with crypt abscesses causing severe tissue damage. The aetiology of UC is unknown but the mucosa contains large numbers of polymorphonuclear leucocytes $(\mathrm{PMN})$ and immunoglobulin secreting plasma cells. ${ }^{1-4}$ Evidence from animal models suggests that an altered immune response to the commensal microflora of the host plays a central role in the development of the condition. ${ }^{3-8}$ Animal models of inflammatory bowel disease (IBD), using knockout or transgenic mice, only acquire characteristic lesions when their colon is populated with normal commensal bacteria, ${ }^{9-15}$ while germ free mice with genetic susceptibility do not develop disease. ${ }^{16}{ }^{17}$

Unlike the normal mucosa, the UC mucosa contains large numbers of IgG plasma cells, reminiscent of a typical peripheral immune response towards an invading pathogen, leading to local deposition of IgG on epithelial cells. ${ }^{18}$ Studies on B cell receptor gene usage of these infiltrating IgG positive lymphocytes demonstrate that they are of peripheral and not mucosal origin in UC versus controls. ${ }^{19} 20$ This has led to the proposal that the UC antibody response is a peripheral response towards bacteria of the normal intestinal microflora that has been translocated to the mucosa, replacing the normal state of mucosal tolerance. ${ }^{20}$ Development of a peripheral immune response in the mucosa is exacerbated by large numbers of infiltrating PMN. The IgG subclass observed in UC mucosa is predominately $\operatorname{IgGl}{ }^{18}$ which has the highest affinity for Fc receptor $\gamma$ I, II, and III (Fc $\gamma$ RI, Fc $\gamma$ RII, Fc $\gamma$ RIII), all of which are present on activated PMN. ${ }^{21}$ FC receptor crosslinking by antibody/antigen complexes is a potent signal for respiratory burst and free radical production by PMN, as observed in IBD, ${ }^{22-26}$ suggesting that the chronic inflammatory state in UC is due to PMN responding to IgG I deposition in the mucosa. This is supported by animal models where local IgG immune complex reactions induced in an already damaged mucosa result in lesions indistinguishable from UC. ${ }^{27}$ However, newer evidence indicates that preexisting physical damage to the mucosa is not necessary for UC initiation as adult colonic epithelial cells express the neonatal FcR (FCRn), ${ }^{28}$ which is able to transcytose IgG and associated antigen bidirectionally across the epithelium. ${ }^{29}$ This would facilitate access of misplaced peripherally derived IgG into the intestinal mucosa where it would interact with bacteria colonising the epithelial surface, and following transcytosis back into the mucosa it could initiate the inflammatory response characteristic of UC. These events would explain involvement of the normal gut microbiota as immunogens in UC, both directly and by inducing crossreactive antibodies against host epithelial antigens. ${ }^{30-35}$

While the vast majority of intestinal bacteria occur in the gut lumen, adherent communities exist in association with the epithelium which are more likely to be involved in UC aetiology but little is known of the species composition or activities of these populations. Anecdotal evidence that antibiotics occasionally induce remission in some UC patients suggests that changes in microbiota species composition can

Abbreviations: APC, antigen presenting cells; $B S A$, bovine serum albumin; CD, Crohn's disease; CFA, cellular fatty acids; ELISA, enzyme linked immunosorbant assay; Fc $\gamma R$, Fc $\gamma$ receptor; FcRn, neonatal Fc receptor; FITC, fluorescine isothiocyanate; HBSS, Hank's balanced salt solution; HY, healthy controls; IBD, inflammatory bowel disease; PBS, phosphate buffered saline; PMN, polymorphonuclear leucocytes; RLU, relative light units; UC, ulcerative colitis; WCA, Wilkins-Chalgren agar 
affect the severity and duration of the condition. ${ }^{36-40}$ Previous studies have addressed the possibility of changes in bacterial composition on the UC rectal mucosa, contributing to maintenance of the chronic inflammatory response, ${ }^{61-43}$ but they have either not identified the organisms to species level ${ }^{41}$ or have focussed on particular groups of bacteria, such as bacteroides and enterobacteria..$^{41}{ }^{43-45}$

If UC is viewed as a systemic immune response misdirected towards the gut mucosa, it can be postulated that systemic antibody responses should reflect changes in mucosal bacterial colonisation in UC patients. As a major source of tissue damage appears to be derived from PMN activation by unknown stimuli, the hypothesis tested in this investigation is that not only is the humoral immune response directed towards mucosal bacteria in UC but that this antibody response opsonises these bacteria, resulting in specific enhancement of PMN respiratory burst.

\section{METHODS}

\section{Patients and controls}

To study mucosal bacterial populations, rectal biopsies were taken from nine patients with active UC who had not received any bowel preparation. None had taken antibiotics in the 28 day period prior to biopsy. Five had pancolitis and four had left sided or distal disease. Diagnosis was confirmed in all cases at colonoscopy and by histology. Three of the nine patients were women and the group had an mean age of 59 years (range 49-90). Mean duration of disease was 8.4 years $(1-20)$. Biopsies were taken from the anterior rectal wall, 5-10 cm from the anal verge. All subjects had actively inflamed mucosa that was categorised as either mild or moderately severe. All biopsies were of inflamed tissue. Ten patients attending the gastroenterology clinic with gastrointestinal symptoms requiring sigmoidoscopy or colonoscopy served as controls. One proved eventually to have Crohn's disease (CD) and was excluded, leaving nine (four females) aged 42 years (range 19-64). The principal diagnoses were irritable bowel $(n=2)$, rectal bleeding $(n=2)$, diverticular disease $(n=1)$, fissure in ano $(n=1)$, antibiotic associated diarrhoea $(\mathrm{n}=1)$, polyp $(\mathrm{n}=1)$, and abdominal pain $(\mathrm{n}=1)$. All nine had normal appearances on sigmoidoscopy, and seven who had rectal biopsies all showed normal histology.

To determine antibody responses against the bacteria identified from the rectal mucosa, banked serum from Biochemical Medicine (Ninewells Hospital) was used. Patients were identified as suffering from either UC $(n=27)$ or $C D(n=24)$, primarily on the basis of pathology reports of multiple colonic biopsies obtained at colonoscopy, or of resection specimens. Notes from 46 of 51 patients were traced and full clinical details obtained for these patients, consistent with the date of blood sample, are summarised in table 1. Eight patients had blood taken post-colectomy and had only the rectum in situ.

Sera from normal healthy controls were obtained from Dundee University Dental School Hospital, where they were undergoing tooth extraction. None was taking antibiotics or any other drugs prior to their visit to the Dental School. Informed patient consent was obtained for these investigations which were approved by the Addenbrookes Hospital Local Research Ethics Committee, Cambridge, and the Tayside Committee on Medical Research Ethics, Dundee.

\section{Experimental design}

Mucosal associated bacteria were isolated and identified from two groups of patients: nine UC and nine healthy controls. These organisms were then used to determine whether a peripheral humoral immune response was targeted against them in three groups of previously diagnosed patients: $27 \mathrm{UC}$, $24 \mathrm{CD}$, and 15 healthy controls. The antibody response (IgG
Table 1 Characteristics of the patients used for systemic antibody responses and opsonisation experiments

\begin{tabular}{lll}
\hline & Ulcerative colitis & Crohn's disease \\
\hline $\mathrm{n}^{*}$ & 27 & 24 \\
Sex (M/F) & $12 / 15$ & $11 / 13$ \\
Age (y)† & $46(17-74)$ & $42(23-72)$ \\
Duration of disease (y)t & $7.9(0-24)$ & $5.8(0-17)$ \\
Anatomical distribution & 16 Pancolitis & 9 Colon only \\
& 8 Left sided or distal & 2 lleal only \\
& & 11 lleocolonic \\
5-ASA drugs & 14 & 7 \\
Systemic or local steroids & 4 & 8 \\
Immunosuppressants & 1 & 4 \\
No IBD specific drugs & 6 & 7 \\
\hline
\end{tabular}

*Total number of patients. Age and sex data are for all patients $(n=51)$. Other data are for patients for whom clinical information was available $(n=46)$.

tMean (range).

5-ASA, 5-aminosalicylic acid; IBD, inflammatory bowel disease.

and IgA) was determined for total bacterial antigens and surface antigens. To determine whether these antibodies specific for the bacterial surface were able to opsonise live bacteria for PMN, respiratory burst experiments were carried out using PMN isolated from normal healthy controls. Selected bacteria, either untreated or coated with antibody from the same patients, were then used for the opsonisation experiments. Finally, the exact nature of the IgG subclass response towards surface antigens of these organisms was measured using purified IgG obtained by pooling the serum from each of the three groups (UC $n=27, C D n=24$, healthy controls $n=15$ ).

Identification of bacteria colonising the rectal mucosa Tissue samples were immediately placed in preweighed sterile Bijoux bottles containing $4 \mathrm{ml}$ sterile anaerobic transport medium (Wilkins-Chalgren broth). The bottles were pre-reduced in anaerobic gas jars (Don Whitley Scientific, Shipley, UK). Dimensions of the tissue samples were measured using a micrometer, after placing them in an anaerobic chamber (atmosphere $10 \% \mathrm{H}_{2}, 10 \% \mathrm{CO}_{2}, 80 \% \mathrm{~N}_{2}$ ) at $37^{\circ} \mathrm{C}$. Weights and physical dimensions of the biopsy materials were used to estimate bacterial cell densities per unit area of epithelial surface.

Biopsies were then macerated using a sterile glass tissue homogeniser. A sample of homogenate $(1 \mathrm{ml})$ was serially diluted (10-fold dilutions to $10^{-5}$ ) in test tubes containing $9 \mathrm{ml}$ half strength sterile anaerobic peptone water. Some of the original sample $(50 \mu \mathrm{l})$ and $100 \mu \mathrm{l}$ of all dilutions to $10^{-5}$ were plated in triplicate onto a range of selective and nonselective culture media. Plates used for isolation of facultative anaerobes were as follows: nutrient agar, total facultative anaerobes; MacConkey agar No 2, lactose fermenting and non-fermenting enterobacteria and enterococci; and Azide blood agar base, facultatively anaerobic cocci. Isolation media for strictly anaerobic bacteria were Wilkins-Chalgren agar (WCA) - total anaerobes, anaerobic cocci, and clostridia; WCA with addition of non-sporing anaerobe supplements; WCA with Gram negative anaerobe supplements; MRS medium, lactobacilli; Perfringens agar plus antibiotic supplements, Clostridium perfringens. Bacteria belonging to the Bacteroides fragilis group were enumerated using Bacteroides mineral salts agar, ${ }^{46}$ while bifidobacteria were counted using Beerens agar. ${ }^{47}$ Plates for aerobic incubation were removed from the anaerobic chamber and incubated at $37^{\circ} \mathrm{C}$ for two days. Anaerobic plates were incubated for five days, with periodic examination, before counting of colonies. Bacteria were then characterised on the basis of their Gram staining characteristics, cellular morphology, fermentation pro- 
ducts, ${ }^{48}{ }^{49}$ and cellular fatty acid (CFA) profiles. Bacterial CFA are highly stable and reproducible taxonomic markers, allowing phenotypic analysis of intestinal microorganisms to be undertaken by extracting these substances and comparing methyl ester profiles by gas chromatography using the MIDI system (Microbial ID Inc., Newark, New Jersey, USA). Colonies for further study were grown on agar plates and removed with sterile swabs into $2 \mathrm{ml}$ freezer vials that were stored at $-80^{\circ} \mathrm{C}$. Unless otherwise stated, all bacteriological culture media and associated antibiotic supplements were obtained from Oxoid (Basingstoke, Hamps, UK).

\section{Bacteria used for immunological studies}

Thirty six different bacterial isolates identified from the biopsies were used for immunological analysis, comprising 24 different species. The full list of organisms used in these experiments is shown in table 2 .

\section{Total IgG and IgA antibody measurements}

Total IgG and IgA in each patient's serum was determined using a radial immnunodiffusion assay. Briefly, $1 \%(\mathrm{w} / \mathrm{v})$ agarose (Kramel Biotech, Northumberland, UK) containing either antihuman IgG or antihuman IgA (Diagnostics Scotland, Edinburgh, UK) was allowed to solidify on glass plates. Either serum or a standard curve of IgG or IgA (Hoffmann-La Roche Ltd, Basel, Switzerland) was applied to holes punched in the agarose. Plates were incubated overnight in a humidified chamber at $37^{\circ} \mathrm{C}$, diffusion rings were visualised with Coomassie blue dye (Sigma, St Louis, Missouri, USA), and the unknown values were determined from the standard curve on each plate.

Table 2 Bacterial isolates tested for systemic antibody responses and abilities to effect respiratory bursts

\begin{tabular}{ll}
\hline Bacterial isolate (strain number) & Source \\
\hline Peptostreptococcus anaerobius (16) & UC \\
Pept anaerobius (22) & UC \\
Pept prevotii & UC \\
Enterococcus faecalis (3) & UC \\
Ent faecalis (5) & UC \\
Clostridium clostridioforme & UC \\
Cl innocuum & UC \\
Cl ramosum & UC \\
Cl malenominatum & UC \\
Cl bifermentans & UC \\
Veillonella parvula & UC \\
Escherichia coli (48) & HY \\
E coli (49) & HY \\
E coli (50) & UC \\
E coli (51) & UC \\
E coli (52) & HY \\
E coli (53) & HY \\
Collinsella aerofaciens & UC \\
Eubacterium limosum & UC \\
Eub rectale & HY \\
Bacteroides fragilis & UC \\
Bact vulgatus (25) & HY \\
Bact vulgatus (32) & UC \\
Bact thetaiotaomicron & UC \\
Bifidobacterium longum & UC \\
Bif breve & UC \\
Bif pseudolongum & UC \\
Bif angulatum & UC \\
Bif bifidum & UC \\
Bif adolescentis (33) & HY \\
Bif adolescentis (21) & HY \\
Bif adolescentis (24) & HY \\
Bif adolescentis (74) & HY \\
Bif adolescentis (75) & HY \\
Lactobacillus paracasei & HY \\
Streptococcus bovis & UC \\
\hline HY, healthy controls; UC, ulcerative colitis. & \\
& \\
\hline
\end{tabular}

\section{$\lg G$ and $\lg A$ antibacterial enzyme linked}

\section{immunosorbant assay (ELISA)}

Pure cultures of rectal bacteria $(25 \mathrm{ml})$ were washed three times in phosphate buffered saline (PBS) and resuspended in PBS. Cells were lysed by two passages through a French pressure cell $\left(1.1 \times 10^{5} \mathrm{kPa}\right)$. Lysates were subsequently coated onto 96 well flat bottomed Easywash EIA plates (Corning Inc, New York, USA) at a 1/100 dilution (equivalent to approximately $1 \times 10^{5}$ cells per well) in carbonate coating buffer at $4^{\circ} \mathrm{C}$ overnight. Plates were washed four times with PBS/0.05\% (v/v) Tween 20, and then blocked using $1 \%$ bovine serum albumin (BSA) solution in PBS/Tween 20. After one hour at $37^{\circ} \mathrm{C}$, plates were emptied and serum was added at a $1 / 100$ dilution in assay buffer for the IgG ELISA, and at a 1/25 dilution for the IgA ELISA. Plates were incubated for one hour at $37^{\circ} \mathrm{C}$ and washed four times, followed by addition of antihuman $\operatorname{IgA}(1 / 2000)$ or $\operatorname{IgG}(1 / 5000)$ horseradish peroxidase conjugated antibody (Sigma). Plates were left for a further hour at $37^{\circ} \mathrm{C}$, washed as before, and the substrate, TMB microwell (KPL, Maryland, USA), was added. The colour was allowed to develop for five minutes and the assay was read at 405/630 nm on a MRXII Microplate Reader (Dynex Technologies, Virginia, USA). Antibody levels are expressed as a ratio of absorbance over concentration of IgG or IgA present in each serum.

\section{Measurement of bacterial specific surface $\lg G$ and $\lg A$ antibodies}

Surface antibodies specific for each organism were determined using the ability of serum to stain the bacterial surface. Bacteria $\left(1 \times 10^{6}\right)$ were incubated at $4^{\circ} \mathrm{C}$ with a $1 / 25$ dilution of sera in $\mathrm{PBS} / 1 \%$ fetal calf serum $/ 0.05 \%$ sodium azide for 30 minutes on ice. They were then washed five times in the same buffer, and a secondary antibody was added: either antihuman $\operatorname{IgG}$ fluorescine isothiocyanate (FITC) or antihuman IgA FITC (Caltag Laboratories, California, USA) and incubated for a further 30 minutes on ice. Comparative levels of antibodies specific for the surface of each bacterium were measured by determining the amount of FITC (fluorescence intensity) on the cell surface (FACScan, Becton Dickinson, USA) compared with a control for each organism, which had no patient sera added. All results are expressed as a ratio of positive fluorescence intensity over total IgG or IgA concentration for each sample.

\section{Purification of $\lg G$ antibodies}

Sera from patients with UC $(n=27), C D(n=24)$, and healthy controls $(n=14)$ were pooled $(50 \mu \mathrm{l}$ from each patient). Total IgG was purified from serum using a protein $G$ column according to the manufacturer's instructions (Sigma). Purity was checked by sodium dodecyl sulphatepolyacrylamide gel electrophoresis. Concentrations of total IgG and IgG subclasses were determined as before, using radial immunodiffusion (The Binding Site, Birmingham, UK). This enabled standardisation of total IgG and IgG subclasses 1, 2, 3, and 4 .

\section{Purification of PMN}

Heparinised peripheral blood $(20 \mathrm{ml})$ was obtained from a healthy control and sedimented to remove red blood cells over 6\% (w/v) Dextran T70 (Amersham Pharmacia, Biotech, Uppsala, Sweden) in sterile $0.9 \%$ saline. The resulting buffy coat was then layered over Ficoll Hypaque (Amersham Pharmacia), and the gradient was centrifuged at $1000 \mathrm{~g}$ for 17 minutes. Cells in the bottom layer were recovered and resuspended in respiratory burst assay buffer at a concentration of $2 \times 10^{6}$ cells $/ \mathrm{ml}$. 


\section{Immune enhancing activity of specific bacterial} antibodies

The abilities of specific bacterial antibodies to enhance PMN respiratory bursts against each organism were measured. Bacteria $\left(1 \times 10^{6}\right)$ were incubated with a $1 / 25$ dilution of patient serum in assay buffer comprising $1 \times$ Hank's balanced salt solution (HBSS) (Invitrogen, Paisley, UK)/ $1 \mathrm{mmol} / \mathrm{l}$ HEPES (Invitrogen), and 1\% BSA for 30 minutes at room temperature. Bacteria were then washed twice in HBSS and applied at $5 \times 10^{5} /$ well to a 96 well plate (Microlitel Removawell Strip, Dynex Technologies), previously blocked with $1 \%$ BSA/PBS solution. Purified peripheral blood PMN $\left(1 \times 10^{5}\right)$ was added to each well with $100 \mathrm{~mol} / \mathrm{l}$ luminol (Sigma) in the assay buffer. Respiratory burst was measured every minute for one hour by following release of luminescence from the luminol. Results are expressed in relative light units (RLU) and total respiratory burst was calculated as the total area under the burst curve.

\section{Antigen specificity of $\lg G 1$ and $\lg G 2$ subclasses}

Eight different bacterial isolates $\left(1 \times 10^{6}\right)$ were stained as described above with either $25 \mu \mathrm{g}$ of total IgG, IgG1, or IgG2. Staining for total IgG was done as before. To measure bound IgG subclasses, a secondary biotinylated mouse antihuman IgG1 or IgG2 (Becton Dickinson) was incubated for 30 minutes on ice. Bacteria were then washed three times and $10 \mu \mathrm{g} / \mathrm{ml}$ of streptavidin/FITC (Sigma) were incubated and washed as previously. Bacteria were analysed by FACScan. Results are expressed as a percentage greater than the binding observed by the relevant IgG obtained from the normal healthy serum pool.

\section{Statistical analyses}

Values for IgG and IgA were considered as continuous variables for comparison. Bacteria in each patient with either UC or CD were compared with a healthy control (that should be defined early) using a Student's $t$ test that determined the statistical significance of an observed difference between the mean values of two study groups. The Student's $t$ test used a two tailed test with groups of unequal variances. Statistical significance was determined at a $\mathrm{p}$ value $\leqslant 0.05$. Statistics were performed using SAS, version 8 (Cary, North Carolina, USA).

\section{RESULTS}

Bacteria isolated from UC and normal rectal biopsies Figure 1 shows the principal groups of bacteria colonising human rectal epithelia in UC patients and healthy subjects. A diverse range of anaerobes and facultative anaerobes were detected in both cohorts, with strict anaerobes belonging to the genera Bacteroides, Prevotella, and Bifidobacterium being numerically predominant in healthy individuals. Mucosal populations in UC patients differed in that bifidobacteria and Prevotella species were present in significantly lower numbers in UC patients $(p<0.05)$. Several other groups of anaerobes were also detected, belonging to the genera Clostridium, Lactobacillus, and Peptostreptococcus, although the latter group were never found in healthy individuals. Similarly, Enterococcus faecalis which is commonly found in faeces was only detected in rectal tissue taken from UC patients (data not shown).

\section{Serum IgG and IgA concentrations}

The UC patient group $(\mathrm{n}=27)$ had $34.0(17.7) \mathrm{mg} / \mathrm{ml}$ total IgG and $2.4(0.4) \mathrm{mg} / \mathrm{ml}$ total IgA. The CD group $(\mathrm{n}=24)$ had similar levels with 30.1 (16.0) $\mathrm{mg} / \mathrm{ml}$ of serum IgG and $2.4(0.6) \mathrm{mg} / \mathrm{ml}$ of total serum IgA. The normal healthy control group $(\mathrm{n}=14)$ had the lowest total IgG $(26.0$ (13.0) $\mathrm{mg} / \mathrm{ml})$ and IgA $(2.3(0.5) \mathrm{mg} / \mathrm{ml})$ levels of the three

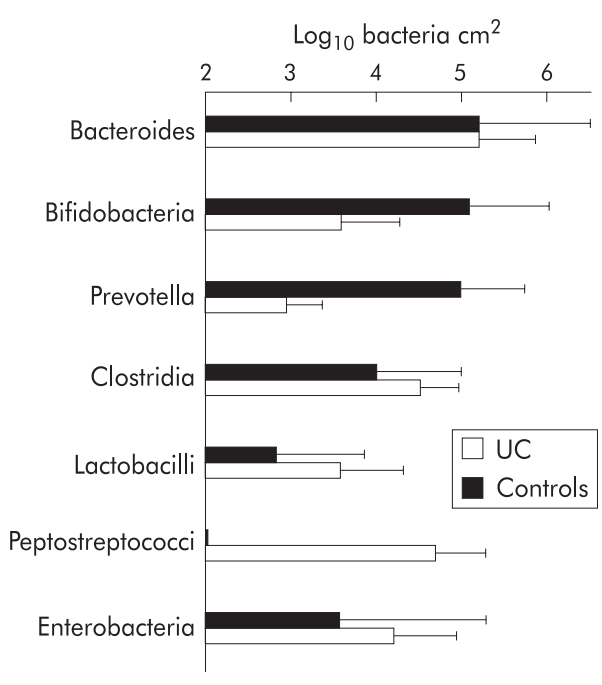

Figure 1 Numerically predominant groups of culturable bacteria colonising the rectal mucosa in ulcerative colitis (UC) patients $(n=9)$ and healthy subjects (Controls) $(n=11)$. Results are means (SD).

experimental cohorts. There was no significant difference in total serum immunoglobulins in the three groups.

\section{Antigen specific $\lg G$ and $\lg A$ antibody responses}

The UC group had higher IgG responses for both Pept anaerobius strains, Ent faecalis, three of the six clostridia tested, and Streptococcus bovis. Significant differences in responses against Pept anaerobius were found $(\mathrm{p}<0.05)$. The remaining isolates tested had the highest IgG responses for total bacterial antigens in the healthy control group, with the response being significantly higher for both Bact fragilis and Bact vulgatus $(\mathrm{p}<0.05)$ compared with the CD and UC groups (fig 2A). This occurred irrespective of whether the organisms originated from a UC patient or a healthy control. Of the 12 bacteria tested for total IgA antibacterial antigen responses (fig $2 \mathrm{~B})$, seven $(58 \%)$ had the highest levels in the healthy control group, two were highest in the CD group, and three had the highest responses in the UC group. Of the eight organisms having the greatest IgG responses in the UC group, only Pept anaerobius (both isolates) showed the same effect with respect to IgA.

\section{$\lg G$ and $\operatorname{Ig} A$ surface antigen responses}

Antibody mediated immune responsiveness to the cell surface of mucosal bacteria was measured for both IgG and IgA serum antibodies (fig 2C, D). Unlike the total antibacterial response, the largest number of $\operatorname{IgG}$ high responders occurred in the UC group, with 59\% of the organisms tested giving the highest responses. Only $12 \%$ of these isolates showed the highest level of response in the healthy control group compared with $78 \%$ for responses to total bacterial antigens (fig 2C). Peptostreptococcus anaerobius IgG responses were significantly higher in the UC cohort $(p<0.05)$ compared with the other groups. This was also true for Veillonella parvula, Clostridium ramosum, E coli (strains 51 and 52), and Bif angulatum.

IgA responses to the surface of these bacteria were broadly similar to IgG reactivities, with only one of the 34 organisms tested showing the highest IgA response in the control group (fig 2D). The UC group again had higher responses against the surface of both Pept anaerobius strains, although they were not statistically significant. Significant differences were recorded for the Ent faecalis (strain 3 ) and E coli (strain 48) $(\mathrm{p}<0.05)$ responses. However, for IgA, differences between 

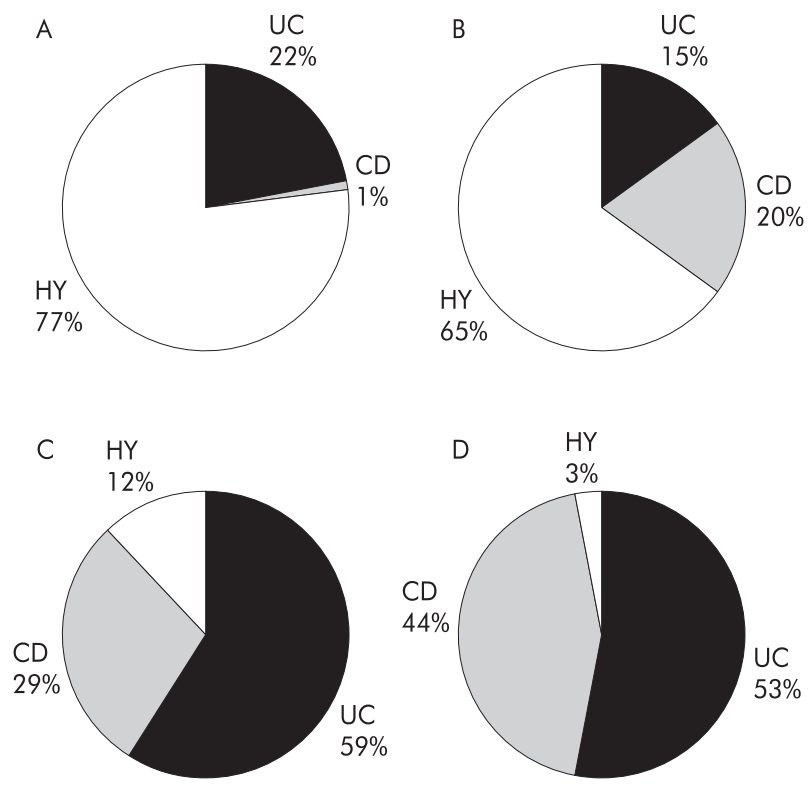

Figure 2 Predominant antibody responsiveness to bacteria isolated from the rectal mucosa. Total antibacterial $\lg G(A)$, total antibacterial $\lg A(B)$, antibacterial surface antigens $\lg G(C)$, and antibacterial surface antigens $\lg A(D)$. Thirty six organisms were studied (see table 2) and the results show the percentage values of these species in each patient group that elicited the highest response. CD, Crohn's disease $(n=24) ; \mathrm{HY}$, healthy controls $(n=15)$; UC, ulcerative colitis $(n=27)$.

UC and CD were minimal, with 18/34 showing the highest responses for UC and 17/34 the highest responses for CD (fig 2D). Many bacteria had $\mathrm{p}$ values approaching significance $(\mathrm{p}<0.1)$ when comparing UC versus controls.

\section{Enhancement of PMN respiratory bursts by UC patient sera}

Respiratory bursts were measured continuously over one hour, and total burst was expressed as a percentage over control, taken as $100 \%$ (table 3 ). Fourteen organisms were assessed in this experiment, and representative respiratory burst curves are shown in fig 3. Sera from UC patients consistently demonstrated enhanced respiratory burst compared with control patients (table 3 ) for all bacteria tested. When the UC group was compared with the control group, significant differences for Pept anaerobius, Bact fragilis, Bact thetaiotaomicron, Ent faecalis, Bif pseudolongum, and Bif longum were seen. The CD group had responses midway between the other two groups. On comparison with the UC group, significant differences occurred with Bact thetaiotaomicron, Ent faecalis, Bif pseudolongum, and Cl clostridioforme $(\mathrm{p}<0.05)$. Analysis of respiratory burst kinetics showed that the UC enhanced burst had a higher peak of luminescence, and that this was reached more rapidly than in either the CD or healthy control groups (fig 3).

\section{Binding of purified IgG to commensal organisms}

To compare specific IgG subclass antibody responses and to normalise concentrations of each antibody, it was necessary to purify the IgG. This also removed competition of binding to the same surface antigens by any $\operatorname{IgA}$ and $\operatorname{IgM}$ in the sera. Results showed that UC total IgG bound at least 100\% better to the eight test organisms (table 4) compared with control IgG at the same concentration. CD total IgG was bound better than the control to some organisms and less well with others, but never reached levels observed with UC IgG. Analysis of binding by IgGl antibodies to the surface of these bacteria demonstrated enhanced binding with UC IgG compared with controls (table 4) whereas the majority of CD IgGl binding was below that of healthy control patients (table 4). The converse was found with IgG2 binding (table 4) where CD IgG2 was directed towards surface antigens of these bacteria to a far greater extent than UC IgG2.

\section{DISCUSSION}

Detailed identification of the bacteria colonising the rectal mucosa of UC patients provides an insight into the changing bacterial populations in a chronically inflamed colon. It also allows determination of the levels of specific circulating antibodies towards the actual colonising bacteria. Furthermore, comparison of the response towards these bacteria in UC and CD demonstrates the similarities between two chronically inflamed conditions of the colon and highlights the differences in their immune activation. UC patients had a significant reduction in bifidobacteria and prevotella, together with higher numbers of clostridia and lactobacilli. Moreover, peptostreptococci and Ent faecalis were uniquely found on the rectal mucosa in UC although the latter had a lower prevalence. Previous work has also reported that peptostreptococci were only found on the rectal mucosa in UC. ${ }^{41}$ Peptostreptococci and enterococci are normal members of the faecal microflora ${ }^{50}$ but do not appear to be able to colonise the mucosal surface in significant numbers in healthy individuals. This could be due to increased bowel movements of a looser composition in $\mathrm{UC}^{1}{ }^{1}$ allowing greater deposition of faecal material on the rectal mucosa, or by leakage of serum proteins and other nutrients across the gut. Alternatively, the UC mucosa may provide a novel ecological niche through expression of different cellular adhesion factors or secreted active peptides such as defensins. ${ }^{51}$ Unlike other studies, ${ }^{45}$ we found no significant differences in total mucosal bacterial numbers in UC.

Immunological studies demonstrated that the systemic immune system has specific IgG and IgA responses to many microorganisms colonising the bowel wall. Most of these bacteria have no overt pathogenic role but it would appear that the immune system monitors bacterial antigens in the colon and raises a systemic immune response towards these organisms. Systemic antibody responses towards total bacterial antigens in the UC group showed changes in the immune response in these patients, such that there was significant stimulation in immune reactivity towards Pept anaerobius for both IgG and IgA. There were also nonsignificant increases in IgG responses towards Ent faecalis, three clostridial species, and Strep bovis, which were all organisms showing increased colonisation in UC. The existence of memory in the antibody response, and the presence of long lasting circulating antibodies, means that it is more likely to detect newly colonising organisms than the loss of response to previously colonising species. The fact that only IgG responses were affected is not surprising as it is mainly this antibody that is increased in UC, specifically IgG $1 . .^{52}$ Not only does the antibody response towards mucosal bacteria increase in UC, but its nature also changes, being directed more towards surface antigens in the UC group.

Evidence from animal models and human studies shows that B cells are needed for induction of full colitis. ${ }^{19} 205354$ In the $\mathrm{T}$ cell receptor alpha knockout mouse model, a systemic oligoclonal antibody response develops towards the normal gut microflora over time, ${ }^{54}$ suggesting that either mucosal B cells are migrating to the periphery or peripheral B cells are recruited to the mucosa and then recirculate back to the periphery. Human studies also point to dysfunction in homing of peripheral $\mathrm{B}$ lymphocytes to the mucosa where $\mathrm{B}$ cell receptor $\mathrm{J}_{\mathrm{H}}$ gene usage, found in mucosal B cells in UC, 
Table 3 Modulation of polymorphonuclear leucocyte respiratory bursts by opsonisation of bacteria isolated from the rectal mucosa using sera obtained from ulcerative colitis patients*

\begin{tabular}{|c|c|c|c|c|}
\hline Bacterial isolate (strain) & UC $(n=21)$ & $C D(n=15)$ & HY $(n=10)$ & $\mathrm{UC} v \mathrm{HY}$ \\
\hline Peptostreptococcus anaerobius (16) & $290(125)$ & $255(105)$ & $193(43)$ & $p=0.0052$ \\
\hline Bacteroides fragilis & $351(213)$ & $276(232)$ & $171(97)$ & $p=0.0049$ \\
\hline Bact vulgatus (32) & $170(103)$ & $134(21)$ & $139(22)$ & NS \\
\hline Bact thetaiotaomicron & $150(32)$ & $128(19)$ & $129(20)$ & $p=0.0436$ \\
\hline Enterococcus faecalis (3) & $263(66)$ & $217(37)$ & $190(29)$ & $p=0.0004$ \\
\hline Clostridium clostridioforme & $259(115)$ & $198(71)$ & 197 (101) & NS \\
\hline Bifidobacterium adolescentis (74) & $154(23)$ & $153(30)$ & 140 (13) & NS \\
\hline Bif bifidum & $198(43)$ & $169(52)$ & $172(39)$ & NS \\
\hline Bif pseudolongum & $254(75)$ & $202(44)$ & 221 (19) & $p=0.0875$ \\
\hline Bif longum & $160(38)$ & $146(44)$ & $107(27)$ & $p=0.0003$ \\
\hline Bif breve & $172(33)$ & $162(52)$ & $160(30)$ & NS \\
\hline Lactobacillus paracasei & $222(104)$ & $198(101)$ & $186(67)$ & NS \\
\hline Escherichia coli (48) & $277(82)$ & 159 (107) & $138(43)$ & NS \\
\hline \multicolumn{5}{|c|}{$\begin{array}{l}\text { *Polymorphonuclear leucocytes (PMN) were isolated from healthy donors. Results are expressed as a percentage of } \\
\text { the control respiratory burst (PMN with unopsonised bacteria were taken as } 100 \% \text { ). The burst was calculated as the } \\
\text { total area under the respiratory burst curve. Results are expressed as the mean (SD) percentage value for each } \\
\text { group of patients. } \\
\text { CD, Crohn's disease; HY, healthy controls; UC, ulcerative colitis. }\end{array}$} \\
\hline
\end{tabular}

is associated with the peripheral repertoire, and not the mucosal B cell repertoire. ${ }^{19}{ }^{20}$ Moreover, the higher IgAl:IgA2 ratio and increase in IgG producing cells in the mucosa of UC patients is characteristic of a more peripheral humoral immune response. ${ }^{55}$ It has also been demonstrated that adhesion molecules, expressed on the endothelium in IBD, may preclude selection of peripheral lymphocytes for migration to the inflamed mucosa. ${ }^{56}{ }^{57}$ Whether this is one of the initiators of UC or a consequence of inflammation is unclear but the destructive role of the antibodies produced is evident. $^{30-34} 5859$ It has been suggested that mechanical damage to tissue is required before bacterial invasion of the mucosa in UC, but peripherally derived plasma cells producing IgG antibody towards members of the commensal microflora could drive inflammatory processes, as IgG can be transported across the epithelium by the FcRn receptor. ${ }^{28}$ This trafficking of IgG is bidirectional, unlike that of IgA, allowing $\operatorname{Ig} G$ to re-enter the mucosa, complete with any bound antigen, thereby exacerbating the existing inflammatory response. ${ }^{29}$ Levels of FcRn in UC epithelial cells are
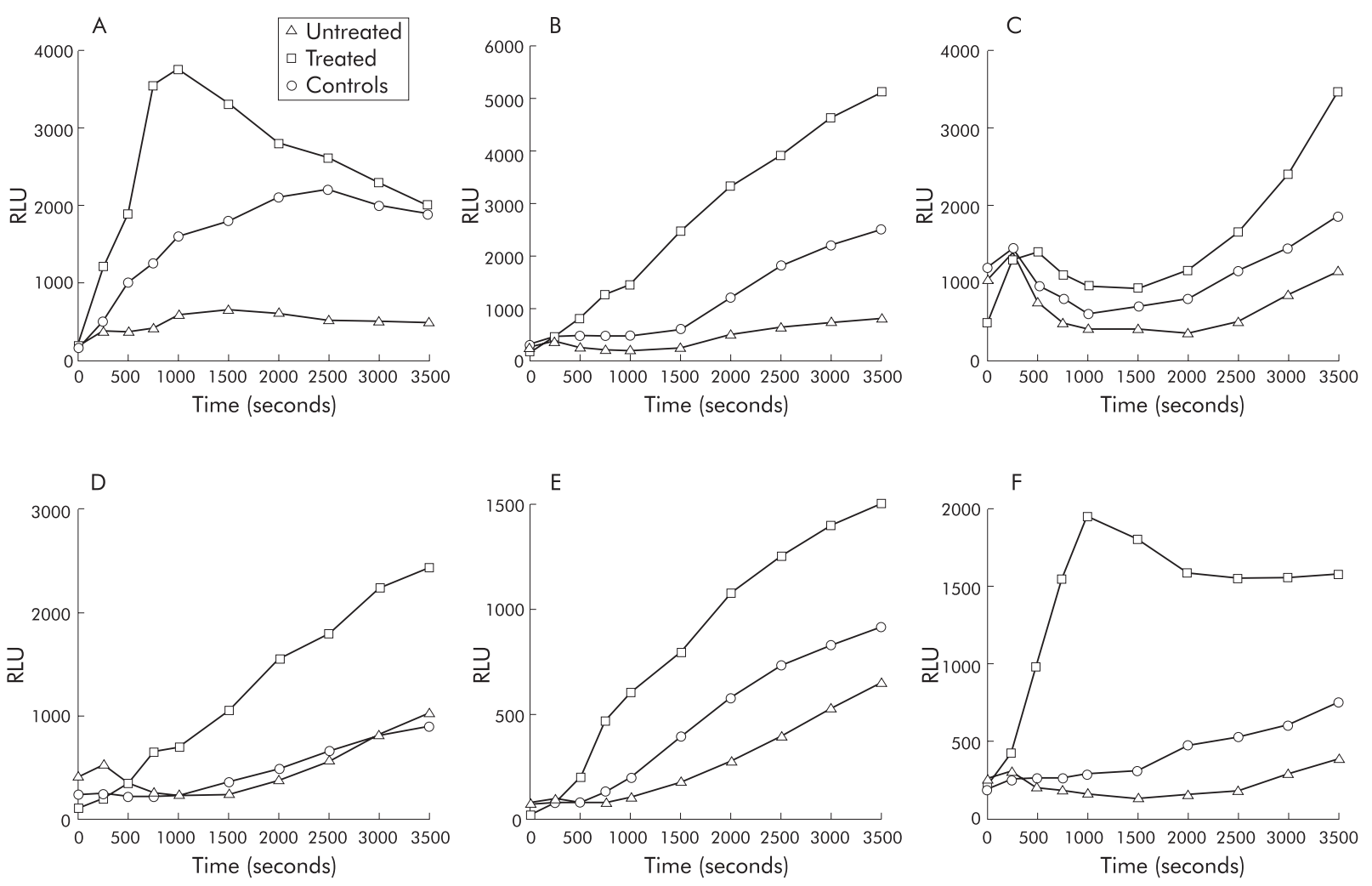

Figure 3 Representative polymorphonuclear leucocyte respiratory bursts against six mucosal isolates: (A) Bacteroides fragilis, (B) Enterococcus faecalis, (C) Escherichia coli, (D) Bifidobacterium longum, (E) Bifidobacterium pseudolongum, and (F) Peptostreptococcus anaerobius, which were untreated, or had been opsonised with sera from ulcerative colitis patients (Treated) or with sera from healthy controls (Controls). Results are expressed as relative light units (RLU) over time. 
Table 4 Reactivity of purified lgG obtained from pooled sera of ulcerative colitis and Crohn's disease patients to different bacterial species isolated from the rectal mucosa*

\begin{tabular}{|c|c|c|}
\hline Bacterial isolates & UC $(n=27)$ & $C D(n=24)$ \\
\hline \multicolumn{3}{|l|}{ Total lg $G$} \\
\hline Peptostreptococcus anaerobius & 138 & 29 \\
\hline Bacteroides fragilis & 104 & -5 \\
\hline Enterococcus faecalis & 111 & -23 \\
\hline Clostridium clostridioforme & 142 & -6 \\
\hline Bifidobacterium adolescentis & 38 & -30 \\
\hline Bif angulatum & 101 & 3 \\
\hline Lactobacillus paracasei & 143 & 33 \\
\hline Escherichia coli & 208 & 60 \\
\hline \multicolumn{3}{|l|}{$\lg G 1$} \\
\hline Peptostreptococcus anaerobius & 114 & 7 \\
\hline Bacteroides fragilis & 47 & -37 \\
\hline Enterococcus faecalis & 100 & -25 \\
\hline Clostridium clostridioforme & 73 & -21 \\
\hline Bifidobacterium adolescentis & 50 & -37 \\
\hline Bif angulatum & 71 & -37 \\
\hline Lactobacillus paracasei & 93 & -21 \\
\hline Escherichia coli & 123 & -6 \\
\hline \multicolumn{3}{|l|}{$\lg \mathrm{L} 2$} \\
\hline Peptostreptococcus anaerobius & 72 & 275 \\
\hline Bacteroides fragilis & -21 & 116 \\
\hline Enterococcus faecalis & 24 & 135 \\
\hline Clostridium clostridioforme & -19 & 44 \\
\hline Bifidobacterium adolescentis & -88 & 60 \\
\hline Bif angulatum & -12 & 110 \\
\hline Lactobacillus paracasei & -29 & 20 \\
\hline Escherichia coli & -14 & 64 \\
\hline \multicolumn{3}{|c|}{$\begin{array}{l}\text { *Results are expressed as a percentage increase/decrease over healthy } \\
\text { donor lgG responses }(n=14) \text {. Concentrations of } \lg G \text { and lgG subclasse } \\
\text { were equalised between the three experimental groups before } \\
\text { immunofluorescence staining. } \\
C D \text {, Crohn's disease; UC, ulcerative colitis. }\end{array}$} \\
\hline
\end{tabular}

unknown but increased mucosal IgG could stimulate expression of this receptor.

Mixing of mucosal and peripheral B cells may also be a feature of the immune response as mice monoassociated with either Lactobacillus paracasei or L johnsonii showed peripheral and mucosal antibody responses to these organisms. ${ }^{60}$ The specific IgG peripheral response depended on the organism used whereby $L$ johnsonii mainly induced $\operatorname{IgGl}$ and $L$ paracase $i$ induced $\operatorname{IgG} 2 \mathrm{a} .{ }^{60}$

The bacteria specific peripheral response in UC versus CD also shows a split in IgG subclass responses but this appears to be disease, rather than organism, specific. The antibacterial IgGl response was associated with UC and the IgG2 response was higher in the CD group, reflecting the type of helper $\mathrm{T}$ cell response predominating in these two conditions. UC and CD may reflect two extremes resulting from a similar genetic background, with disease outcome influenced by environmental factors during initiation. This is supported by observations that siblings of similar genetic susceptibility for IBD develop CD or UC, depending on whether or not they smoke. $^{61}$

Antibacterial antibody enhancement of PMN innate immune responses is called opsonisation. This study demonstrated a higher level of (IgGl) antibodies towards surface antigens in the UC group that would enhance the respiratory burst against their own commensal organisms, thereby maintaining the chronic inflammatory state. UC patients do have increased opsonisation potential for mucosal bacteria. While CD patients had increased antibody responses towards surface antigens on some bacteria, notably Bacteroides fragilis, UC patients manifested an increased ability to opsonise PMN responses in all cases. This may be due to the higher affinity of IgG1 for Fc $\gamma$ RII compared with IgG2. ${ }^{21} \operatorname{IgG} 2$ recognition is further restricted because only some Fc $\gamma$ RII allotypes are able to bind. ${ }^{21}$ This may partly explain variations observed in the respiratory burst results. The respiratory burst induced by bacteria opsonised with UC serum was consistently more rapid and of a higher magnitude, indicating greater numbers of Fc receptors being ligated. Enhancement of respiratory burst could be due to increased antigen specific IgGl in the UC samples. Physiologically, this potential for greatly enhanced activation of PMN in the UC mucosa would lead to release of inflammatory mediators. ${ }^{22-26}$ Recent work has shown that faecal levels of calprotectin, a component of PMN cytoplasm, could predict relapse in IBD. ${ }^{62}$

In conclusion, this investigation demonstrated differences in bacterial colonisation of the rectal mucosa in UC patients that was reflected in systemic IgG responses towards these organisms. These antibodies opsonised mucosal bacteria greatly enhancing PMN respiratory bursts. The existence of circulating antibodies reflects changing B cell responses, both in the mucosa where the antigen resides and in the periphery where extraintestinal symptoms of UC, which are primarily antibody driven, occur. ${ }^{58}$

\section{ACKNOWLEDGEMENTS}

We wish to acknowledge the help of Dr Douglas Steinke as a statistical consultant and Mr R Potts for the IgG subclass measurements. The work was funded by the Medical Research Council, UK.

\section{Authors' affiliations}

E Furrie, S Macfarlane, G T Macfarlane, MRC Microbiology and Gut Biology Group, University of Dundee, Ninewells Hospital and Medical School, Dundee, UK

J H Cummings, Department of Molecular and Cellular Pathology, University of Dundee, Ninewells Hospital and Medical School, Dundee, UK

\section{REFERENCES}

1 Podolsky DK. Inflammatory bowel disease (First of two parts). N Engl J Med 1991;325:928-37.

2 Farrell RJ, Peppercorn MA. Ulcerative colitis. Lancet 2002;359:331-40.

3 Macdonald TT, Monteleone G, Pender SLF. Recent developments in the immunology of inflammatory bowel disease. Scand J Immunol 2000;51:2-9.

4 McAlindon ME, Gray T, Galvin A, et al. Differential lamina propia cell migration via basement membrane pores of inflammatory bowel disease mucosa. Gastroenterology 1998;115:841-8.

5 Campieri M, Gionchetti P. Bacteria as the cause of ulcerative colitis. Gut 2001;48:132-5.

6 Schultsz C, Van Den Berg FM, Ten Kate FW, et al. The intestinal mucus layer from patients with inflammatory bowel disease harbors high numbers of bacteria compared with controls. Gastroenterology 1999;1 17:1089-97.

7 Butcher EC. Leukocyte-endothelial cell recognition: three (or more) steps to specificity and diversity. Cell 1991;67:1033-6.

8 Duchmann R, Kaiser I, Hermann E, et al. Tolerance exists towards resident intestinal flora but is broken in active inflammatory bowel disease (IBD). Clin Exp Immunol 1995; 102:448-55.

9 Elson CO, Sartor RB, Tennyson GS, et al. Experimental models of inflammatory bowel disease. Gastroenterology 1995;109:1344-67.

10 Ehrhardt RO, Ludviksson BR, Gray B, et al. Induction and prevention of colonic inflammation in IL-2-deficient mice. J Immunol 1997; 158:566-73.

11 Bhan AK, Mizoguchi E, Neal Smith R, et al. Colitis in transgenic and knockout animals as models of human inflammatory bowel disease. Immunol Rev 1999; 169:195-207.

12 Onderdonk AB, Richardson JA, Hammer RE, et al. Correlation of fecal microflora of HLA-B27 transgenic rats with inflammatory bowel disease. Infect Immun 1998:66:6022-3.

13 Rath HC, Herfarth HH, Ikeda JS, et al. Normal luminal bacteria, especially Bacteroides species, mediate chronic colonic, gastric, and systemic inflammation in HLA-B27/hb2m transgenic rats. J Clin Invest 1996:98:945-53.

14 Rath HC, Schultz M, Freitag R, et al. Different subsets of enteric bacteria induce and perpetuate experimental colitis in rats. Infect Immun $2001 ; 69: 2277-85$

15 Sellon RK, Tonkonogy S, Schultz M, et al. Resident enteric bacteria are necessary for the development of spontaneous colitis and immune system activation in IL-10 deficient mice. Infect Immun 1998:66:5224-31.

16 Sadlack B, Merz H, Schorle H. Ulcerative colitis-like disease in mice with a disrupted interleukin-2 gene. Cell 1993;75:253-61.

17 Taurog JD, Richardson JA, Croft JT, et al. The germ free state prevents development of gut and joint inflammatory disease in HLA-B27 transgenic rats. J Exp Med 1994; 180:2359-64.

18 Kett K, Rognum TO, Brandtzaeg P. Mucosal subclass distribution of immunoglobulin G-producing cells is different in ulcerative colitis and Crohn's disease of the colon. Gastroenterology 1987;93:919-24. 
19 Dunn-Walters DK, Boursier L, Hackett M, et al. Biased JH. usage in plasma cell immunoglobulin gene sequences from colonic mucosa in ulcerative colitis but not in Crohn's disease. Gut 1999;44:382-6.

20 Thoree VC, Golby SJC, Boursier L, et al. Related lgA 1 and $\lg G$ producing cells in blood and diseased mucosa in ulcerative colitis. Gut 2002:51:44-50.

21 Ravetch JV, Clynes RA. Divergent roles for Fc receptors and complement in vivo. Ann Rev Immunol 1998; 16:421-32.

22 Grisham MB. Oxidants and free radicals in inflammatory bowel disease. Lancet 1994;344:859-61.

23 Beckman JS, Beckman TW, Chen J, et al. Apparent hydroxyl radical production by peroxynitrite: implications for endothelial injury from nitric oxide and superoxide. Proc Natl Acad Sci U S A 1990;87:1620-4.

24 Shiratora Y, Aoki S, Takada H, et al. Oxygen-derived free radical generating capacity of polymorphonuclear cells in patients with ulcerative colitis. Digestion 1989:44:163-71.

25 Simmonds NJ, Allen RE, Stevens TR, et al. Chemiluminescence assay of mucosal reactive oxygen metabolites in inflammatory bowel disease. Gastroenterology 1992;103:186-96.

26 McKenzie SJ, Baker MS, Buffinton GD, et al. Evidence of oxidant-induced injury to epithelial cells during inflammatory bowel disease $J$ Clin Invest 1996;98:136-41

27 Hodgson HJ, Potter BJ, Skinner J, et al. Immune complex mediated colitis in rabbits. An experimental model. Gut 1978;19:225-32.

28 Israel EJ, Taylor S, Wu Z, et al. Expression of the neonatal Fc receptor, FcRn, on human intestinal epithelial cells. Immunology 1997;92:69-74.

29 Dickinson BL, Badizadegan K, Wu Z, et al. Bidirectional FcRn-dependent lgG transport in a polerised human intestinal epithelial cell line. J Clin Invest 1999;104:903-11.

30 Saxon A, Shanahan F, Landers C, et al. Distinct subset of antineutrophil cytoplasmic antibodies is associated with inflammatory bowel disease. J Allerg Clin Immunol 1990;86:202-21.

31 Snook JA, Lowes JR, Wu KC, et al. Serum and tissue autoantibodies to colonic epithelium in ulcerative colitis. Gut 1991;32:163-6.

32 Seibold F, Brandwein S, Simpson S, et al. pANCA represents a crossreactivity to enteric bacterial antigens. J Clin Immunol 1998;18:153-60.

33 Cohavy O, Bruckner D, Gordon LK, et al. Colonic bacteria express an ulcerative colitis pANCA-related protein epitope. Infect Immun 2000;68: 1542-8.

34 Wei B, Harnisha D, Gordon LK, et al. Molecular cloning of a Bacteroides caccae TonB-linked outer membrane protein identified by an inflammatory bowel disease marker. Infect Immun 2001;69:6044-54.

35 Khoo UY, Bjarnason I, Donaghy A, et al. Antibodies to colonic epithelial cells from the serum and colonic washings in ulcerative colitis. Gut 1995;37:63-70.

36 Dickinson RJ, O'Connor HJ, Pinder I, et al. Double blind controlled trial of oral vancomycin as adjunctive treatment in acute exacerbations of idiopathic colitis. Gut 1985;26:1380-4.

37 Mantzaris GJ, Hatzis A, Kontogiannis P, et al. Intravenous tobramycin and metronidazole as an adjunct to corticosteroids in acute, severe ulcerative colitis. Am J Gastroenterol 1994;89:43-6.

38 Turunen UM, Farkkila MA, Hakala K, et al. Long-term treatment of ulcerative colitis with ciprofloxacin: a prospective, double-blind, placebo-controlled study. Gastroenterology 1998;115:1072-8.

39 Present DH. Ciprofloxacin as a treatment for ulcerative colitis-not yet. Gastroenterology 1998;115:1289-91.

40 Cummings JH, Macfarlane GT. Is there a role for microorganisms? In: Jewell DP, Warren BF, Mortensen NJ, eds. Challenges in inflammatory bowel disease. Oxford: Blackwell Science, 2001:47-8.

41 Matsuda H, Fujiyama Y, Andoh A, et al. Characterisation of antibody responses against rectal mucosa-associated bacterial flora in patients with ulcerative colitis. J Gastroenterol Hepatol 2000;15:61-8.
42 Hartley MG, Hudson MJ, Swarbrick ET, et al. The rectal mucosa associated microflora in patients with ulcerative colitis. J Med Microbiol 1992;36:96-103.

43 Poxton IR, Brown R, Sawyer A, et al. Mucosa-associated bacterial flora in the human colon. J Med Microbiol 1997;46:85-91.

44 Macpherson A, Khoo UY, Forgacs I, et al. Mucosal antibodies in inflammatory bowel disease are directed against intestinal bacteria. Gut 1996;38:365-75.

45 Swidsinski A, Ladhoff A, Pernthaler A, et al. Mucosal flora in inflammatory bowel disease. Gastroenterology 2002;122:44-54.

46 Macfarlane GT, Hay S, Macfarlane S. Effect of different carbohydrates on growth, polysaccharidase and glycosidase production by Bacteroides ovatus, in batch and continuous culture. J Appl Bacteriol 1990;68:179-87.

47 Beerens $\mathrm{H}$. An elective and selective isolation medium for Bifidobacterium spp. Lett Appl Bacteriol 1990;11:155-7.

48 Macfarlane GT, Cummings JH, Allison C. Protein degradation by human intestinal bacteria. J Gen Microbiol 1986;132:1647-56.

49 Macfarlane S, Quigley ME, Hopkins MJ, et al. Effect of retention time on polysaccharide degradation by mixed populations of human colonic bacteria studied under multi-substrate limiting conditions in a three-stage compound continuous culture system. FEMS Microbiol Ecol 1998;26:231-43.

50 Ducluzeau R. Role of experimental microbial ecology in gastroenterology. In: Bergogne-Benezin, ed. Microbial ecology and intestinal infections. Paris: Springer-Verlag, 1989:7-26

51 Fahlgren A, Hammarstrom S, Danielsson A, et al. Increased expression of anti-microbial peptides and lysozyme in colonic epithelial cells of patients with ulcerative colitis. Clin Exp Immunol 2003;131:90-101.

52 Gouni-Berthold I, Baumeister B, Berthold HK, et al. Immunoglobulins and IgG subclasses in patients with inflammatory bowel disease. Hepatogastroenterology 1999;46:1720-3

53 Mombaerts P, Mizoguchi E, Grusby MJ, et al. Spontaneous development of inflammatory bowel disease in T cell receptor mutant mice. Cell 1993;75:274-82

54 Mizoguchi A, Mizoguchi E, Tonegawa S, et al. Alteration of a polyclonal to an oligoclonal immune response to cecal aerobic bacterial antigens in TCR $\alpha$ mutant mice with inflammatory bowel disease. Int Immunol 1996:8:1387-94.

55 Andre $C$, Andre F, Fargier C. Distribution of $\lg A 1$ and $\lg A 2$ plasma cells in various normal human tissues and in the jejunum of plasma $\lg A$-deficient patients. Clin Exp Immunol 1978;33:327-31.

56 Salmi M, Kalimo K, Jalkanen S. Induction and function of vascular adhesion protein-1 at sites of inflammation. J Exp Med 1993;178:2255-60.

57 Salmi M, Granfors K, MacDermott R, et al. Aberrant binding of lamina propria lymphocytes to vascular endothelium in inflammatory bowel disease. Gastroenterology 1994;106:596-605.

58 Snook JA, De Silva HJ, Jewell DP. The association of autoimmune disorders with inflammatory bowel disease. Q J Med 1989;72:835-40.

59 Quinton JF, Sendid B, Reumaux D, et al. Anti-Saccharomyces cerevisiae mannan antibodies combined with antineutrophil cytoplasmic autoantibodies in inflammatory bowel disease: prevalence and diagnostic role. Gut 1998;42:788-91

60 Ibnou-Zekri N, Blum S, Schiffrin EJ, et al. Divergent patterns of colonization and immune response elicited from two intestinal lactobaccilus strains that display similar properties in vitro. Infect Immun 2003;71:428-36.

61 Bridger S, Lee JCW, Bjarnason I, et al. In siblings with similar genetic susceptibility for inflammatory bowel disease, smokers tend to develop Crohn's disease and non-smokers develop ulcerative colitis. Gut 2002;51:21-5

62 Tibble JA, Sigthorsson G, Bridger S, et al. Surrogate markers of intestinal inflammation are predictive of relapse in patients with inflammatory bowel disease. Gastroenterology 2000;1 19:15-22. 